Kansas State University Libraries

New Prairie Press

\title{
PREDICTING THE DATE OF FIRST CATCH OF THE CORN EARWORM, HELICOVERPA ZEA, IN CENTRAL U.S.
}

\author{
J. H. Matis \\ S. Yang \\ N. Castiaux \\ J. K. Westbrook \\ K. R. Beerwinkle
}

See next page for additional authors

Follow this and additional works at: https://newprairiepress.org/agstatconference

Part of the Agriculture Commons, and the Applied Statistics Commons

\section{(c) (1) $9 \Theta$}

This work is licensed under a Creative Commons Attribution-Noncommercial-No Derivative Works 4.0 License.

\section{Recommended Citation}

Matis, J. H.; Yang, S.; Castiaux, N.; Westbrook, J. K.; Beerwinkle, K. R.; and Lopez, J. D. Jr. (1995). "PREDICTING THE DATE OF FIRST CATCH OF THE CORN EARWORM, HELICOVERPA ZEA, IN CENTRAL U.S.," Conference on Applied Statistics in Agriculture. https://doi.org/10.4148/2475-7772.1332

This is brought to you for free and open access by the Conferences at New Prairie Press. It has been accepted for inclusion in Conference on Applied Statistics in Agriculture by an authorized administrator of New Prairie Press. For more information, please contact cads@k-state.edu. 


\section{Author Information}

J. H. Matis, S. Yang, N. Castiaux, J. K. Westbrook, K. R. Beerwinkle, and J. D. Lopez Jr. 


\title{
PREDICTING THE DATE OF FIRST CATCH OF THE CORN EARWORM, HELICOVERPA ZEA, IN CENTRAL U.S.
}

by

J.H. Matis ${ }^{1}$, S. Yang ${ }^{1}$, N. Castiaux ${ }^{2}$, J.K. Westbrook ${ }^{3}$, K.R. Beerwinkle ${ }^{3}$ and J.D. Lopez, Jr. ${ }^{3}$

1. Department of Statistics, Texas A\&M University, College Station, TX 77843-3143

2. Mapping Science Laboratory, Texas A\&M University, College Station, TX 77843-2135

3. Areawide Pest Management Research Unit, USDA - ARS, 2771 F\&B Road, College Station, TX 77845

\begin{abstract}
This paper develops predictive (or correlative) models for the date of first catch of the corn earworm, Helicoverpa zea, as a basis for identifying biotic and abiotic factors that influence dispersal and migration. Data described in Goodenough et al. (1988, J. Econ. Entomol.) on the catch of $H$. zea gathered at over 150 sites predominantly in the central U.S. from 1983 to 1986 are analyzed. The dependent variables, $Y_{1}$ and $Y_{2}$, are date of first meaningful catch and date when cumulative catch exceeds 5, respectively; the independent variables are latitude, longitude and elevation of the site. Outstanding among the findings are the following:

1) There is no statistical evidence based on all the data that the slopes of the simple linear regression models of $Y_{2}$ on latitude differ among the four years. The common slope estimate is 8.11 days/degree, the intercepts differ by as many as 16 days, and the combined model has $r^{2}=0.69$.

2) There is no statistical evidence based on the data in the central U.S. that the partial slopes of the multiple regression models of $Y_{2}$ on latitude and longitude differ among the four years. The common partial slope estimates are 7.36 and -1.27 days/degree, the intercepts differ by as many as 17 days, and the combined model has $R^{2}=0.69$. Second order terms are not significant.

3) An exploratory analysis using GIS mapping software suggests that elevation is also a significant predictor variable. The suggestion is confirmed in multiple regression models for both $Y_{1}$ and $Y_{2}$, with $R^{2}=0.71$ and 0.72 respectively. The intercepts differ by as many as 20 and 17 days, respectively, over the four years.
\end{abstract}

These results imply that the time of first appearance at any location in the central U.S. could be predicted once the date of first appearance in South Texas is ascertained. They also demonstrate the utility of analyzing residuals using GIS mapping software. Research is in progress to investigate other possible predictor variables including soil moisture, soil temperature and precipitation. 


\section{Introduction}

The corn earworm, Helicoverpa zea (Boddie), is one of the most destructive agricultural pests of the Americas. Corn, the primary host of $H$. zea, acts as a nursery crop which produces large numbers of the adults that migrate after the crop matures. Understanding the migratory capabilities of the highly mobile $H$. zea is pivotal in developing successful control strategies.

A previous study, Goodenough et al. (1987), found that the dates of first catch at individual locations varied considerably among years, but that the estimated slopes in the regression models of date of first catch on latitude agreed closely from year to year. This paper first extends the simple linear regression models of the previous study, and then develops multiple regression models based on latitude and longitude. The residuals from such models are investigated to suggest other environmental factors which might be included as independent variables. The general objective of this study is to develop predictive (correlative) models for the date of first catch of $H$. zea as a basis for identifying biotic and abiotic factors that influence dispersal and migration. These factors would then be incorporated into biophysical (mechanistic) models of use in developing management strategies for moth populations.

\section{Data and Methods}

Data on the catch of $H$. zea over time were gathered at various sites from 1983 to 1986 using sex pheromone traps. The complete list of sites and the number of traps at each site are given in Goodenough et al. (1987). These sites, over 150 in total, were predominantly in the central U.S. Data are available from some sites only for a single year.

Two variables were defined to measure the day of year (DOY) of first catch at a location. Let

$$
\begin{aligned}
& Y_{1}=\text { DOY of "first meaningful catch", when a mean of } 3 \text { or more } H \text {. zea per day per } \\
& \text { trap were caught for the first time, and } \\
& Y_{2}=\text { DOY when the cumulative catch (or "sum") per trap exceeded } 5 \text { for the first } \\
& \text { time. }
\end{aligned}
$$

$Y_{1}$ and $Y_{2}$ could not be estimated at the few locations with a nonzero catch at the time of first trap service, hence such locations were eliminated from the present study. The sample sizes for the four years are $60,86,105$ and 125 respectively.

Contour maps of $Y_{1}$ and $Y_{2}$ were obtained for each of the four years using S-PLUS (Mathsoft, 1993). Figure 1 gives these contour maps for $Y_{2}$; similar maps are given in Goodenough et al. (1988). Full color contour maps were obtained using the ARC/INFO GIS system (ESRI, 1991). Such color maps are especially useful in visualizing the spatial variability in $Y_{1}$ and $Y_{2}$. These maps are not given in the present paper, but are available from the senior author. Figure 1 also illustrates the corresponding grey scale contour plots of $Y_{2}$, as well as the sampling locations, for each of the four years. The contour maps for $Y_{1}$ are similar to those for $Y_{2}$, and are not presented.

We analyzed these data using standard regression methodology (see e.g. Neter et al., 1992) to investigate common patterns of movement and to develop optimum predictive equations. Particular attention was given to analyzing the residuals in a spatial context. At the present time, the standard commercial GIS software packages do not have such statistical analysis capability, though clearly such analyses may be extremely useful. 


\section{Results for Models with Latitude or Longitude Alone.}

Simple linear regression models for $Y_{1}$ and $Y_{2}$, where the independent variable is either latitude, denoted $X_{1}$, or longitude, denoted $X_{2}$, were considered first. Symbolically, the models with latitude are:

$$
Y_{1}, Y_{2}=\beta_{0}+\beta_{1} X_{1}+\epsilon
$$

The slope $\beta_{1}$ may be interpreted as the number of days required for the first appearance of H.zea adults to progress northward $1^{\circ}$ of latitude. The intercept $\beta_{0}$ is also essential to determine the mean date of first catch at any given location. The random error terms, denoted $\epsilon$, are assumed to have independent normal distributions with constant variance. Spatial statistical models (see e.g. Cressie, 1993) where the error terms are spatially correlated, were not considered for the present data due to the large geographical scale with complex heterogeneity among the sampling locations.

The results are given for both $Y_{1}$ and $Y_{2}$ in Table 1 for each individual year and for the combined years. All of the models are highly significant $(p<0.001)$. The findings are consistent with Goodenough et al. (1988) which reports estimates $b_{0}=-163$ and $b_{1}=8.18$, and $r^{2}=0.70$ for the model of $Y_{1}$ from the combined data from three years, 1983-1985.

The simple linear regression models with longitude, $X_{2}$, are

$$
Y_{1}, Y_{2}=\beta_{0}+\beta_{1} X_{2}+\epsilon
$$

with similar interpretation and assumptions as in model 1 . The results for these models are given in Table 2. All of the models are highly significant $(p<0.001)$ except for year 1984 . In general, the results indicate an easterly component in the direction of first occurrence.

In order to develop predictive models which would be useful for forecasting dates of first catch, two hypotheses were tested: 1) the equality of slopes from year to year and 2) assuming equal slopes, the equality of intercepts from year to year.

There is no statistical evidence $\left(F_{3,350}=0.94, p>0.50\right)$ that the slopes for predicted $Y_{2}$ differ among the four years for model 1 , based on latitude. The estimated common slope from a model with four intercepts is $b_{1}=8.11$, as given in Table 3 . The hypothesis of equal intercepts is rejected $\left(F_{3,350}=8.55, p<0.01\right)$. The four estimated intercepts are -167.2 , 169.7, -154.7 , and -153.3 , which differ by as many as 16.4 days. This combined model for the four years with common slope but different intercepts has $r^{2}=0.69$.

The slopes for predicted $Y_{1}$ are significantly different $\left(F_{3,350}=2.63, p=0.049\right)$ for the four years in model 1. It is apparent in Table 1 that this difference is due to the much lower slope estimate in 1986, which is associated with the higher estimated intercept. Assuming a common slope, the estimate is $b_{1}=7.97$. The four estimated intercepts for this model are $-158.0,-160.4,-141.4$, and -136.8 , which differ by as many as 23.6 days. The combined model has $r^{2}=0.65$.

These results suggest that $Y_{2}$ is predictable in subsequent years also. There is no evidence that the rates of northward occurrence differ from year to year. Figure 2A illustrates the estimated 
regression lines for the four years for $Y_{2}$ assuming the common slope. The difference in predicted DOY for $Y_{2}$ at any given location by as many as 16.4 days from year to year is apparent in the graphs. This compares with a finding in Goodenough et al. (1988) that, for locations with data for three years, the DOY of first capture differ by a mean of 29 days. In principle, once the DOY for $Y_{2}$ is established in South Texas for a given year, one could forecast $Y_{2}$ successfully at locations further north.

Forecasting of $Y_{1}$ based on latitude alone is more problematical, despite the comparable $r^{2}$. The low slope in 1986 is confounded with a unique sampling design that year which had a large number of sampling locations in the Northeast.

These tests are also conducted for model 2 based on longitude. There is no statistical evidence that the slopes of predicted $Y_{1}$ and $Y_{2}$ differ over the four year $\left(F_{3,350}=0.30\right.$ and $\left.F_{3,350}=0.55\right)$. The estimated regression lines for predicted $Y_{2}$, assuming a common slope for the four years, are also illustrated in Figure 2A. The intercepts differ by no more than 26.9 days, which is consistent with Goodenough et al. (1988). Clearly, the $r^{2}$ values of only 0.23 and 0.19 rule out the use of model 2 as a primary equation for predicting DOY of insect catch. However, the use of longitude, $X_{2}$, might be of great benefit in a multiple regression model.

\section{Results for Models with Latitude and Longitude}

\subsection{First Degree Terms Only}

Consider multiple regression models for $Y_{1}$ and $Y_{2}$. The first order models are

$$
Y_{1}, Y_{2}=\beta_{0}+\beta_{1} X_{1}+\beta_{2} X_{2}+\epsilon
$$

The sampling locations differ greatly over the years, with a number of sites in California in 1983 only, and with numerous sites in the Northeast in 1986. In order to minimize effects which might be specific to only certain parts of the U.S., locations are included only with longitude between 80 and 110 degrees. This central U.S. region is common to all four years, and has sample sizes of 53, 86, 91 and 87 respectively. The results from model 3 for this central region are given in Table 4 for each year and for the combined years.

In general, the $R^{2}$ values in Table 4 with the restricted range of longitude are somewhat lower than the corresponding $R^{2}$ values for the models (not reported here) with an unrestricted range. However, in no case is the drop more than 0.04. Although the data in Tables 1 and 4 are a bit different, it is apparent that the inclusion of longitude tends to increase $R^{2}$, sometimes substantially as in 1983. Each partial slope, i.e. the hypothesis $H_{0}: \beta_{\mathrm{i}}=0$ for $i=1,2$; is tested in each model. Each estimated slope is significant ( $\mathrm{p}<0.02$ in each case) except for $b_{2}$ (for longitude) in the model of $Y_{2}$ in 1984 and 1986. The $b_{0}$ estimates vary widely, reflecting the expected increase in the standard errors of these estimates with the addition of another variable.

The hypotheses of common partial slopes $\left(\beta_{1}\right.$ and $\left.\beta_{2}\right)$, and also of common intercepts $\left(\beta_{0}\right)$ given common slopes, are again tested. There is no evidence that the partial slopes differ for the model of $Y_{2}\left(F_{6,350}=1.45, p>0.10\right)$, however the partial slopes are significantly different for the model of $Y_{1}\left(F_{6,350}=2.13, p=0.049\right)$. The hypothesis of equal intercepts is rejected in both cases. The estimated equations with common slopes are: 


$$
\begin{gathered}
\hat{\mathrm{Y}}_{1}=b_{01}+7.65 X_{1}-1.82 X_{2} \text {, and } \\
\hat{\mathrm{Y}}_{2}=b_{02}+7.36 X_{1}-1.27 X_{2} .
\end{gathered}
$$

where $b_{01}=33.3,25.3,39.2$, and 47.1 , and $b_{02}=-90.4,-96.8,-85.8$, and -80.0 , respectively, for the four years. The $R^{2}$ values are 0.68 and 0.69 .

These results from model 3 indicate that both the rate and the northeasterly direction of first appearance are approximately the same for $Y_{2}$ from year to year. The predicted DOY of $Y_{2}$ at any location differs by as many as 16.8 days for the four years. Though the $R^{2}$ for model 4 for multiple years is generally lower than the $R^{2}$ for the single year models, model 4 provides a framework for predictive modeling of $Y_{2}$. In practical application, once the date of first catch $\left(Y_{2}\right)$ in South Texas is ascertained, one could predict first capture times for the given year at other locations in the central U.S. by using equation 4. $Y_{1}$ is also predictable, but requires greater caution.

\subsection{Second Order Models}

Consider now the following second order models for the central U.S. data:

$$
Y_{1}, Y_{2}=\beta_{0}+\beta_{1} X_{1}+\beta_{2} X_{2}+\beta_{3} X_{1}^{2}+\beta_{4} X_{1} X_{2}+\beta_{5} X_{2}^{2}+\epsilon .
$$

The models add curvature and interaction to the prediction equations.

Two types of hypotheses were tested in model 5 . The first is the significance of each of the second degree partial regression coefficients, i.e. $H_{0}: \beta_{\mathrm{i}}=0$ for $i=3,4,5$; in the model. The $R^{2}$ values for the full models and the results for testing each second degree term for both $Y_{1}$ and $Y_{2}$ for each year are given in Table 5. Only in 1983 is there any evidence of a significant second order effect. The second hypothesis tests the joint significance of all second degree terms, i.e. $H_{0}: \beta_{3}=\beta_{4}=\beta_{5}=0$ in model 5 . The hypothesis is rejected only in 1983, for both $Y_{1}$ and $Y_{2}$, due to the quadratic effect of longitude. Consequently, for simplicity, we retain equations 4 as the general predictive models based on latitude and longitude.

\section{Search for Other Variables}

\subsection{Spatial Analysis of Residuals}

One important objective of the project is to identify other possible variables which might influence insect appearance. Such possible variables include measures of precipitation, temperature, prevailing wind, and elevation. For this purpose, the residuals of $Y_{1}$ and $Y_{2}$ from model 4 were plotted on a map, as given in Figure 3 for $Y_{2}$. One immediate conclusion is that negative residuals occurred consistently in locations adjacent to the Mississippi River, and positive residuals occurred regularly in the New Mexico locations. The effect is particularly striking in color contour plots. This suggests the addition of elevation to the predictive models. 


\subsection{Models with Elevation}

Consider generalizing model 3 to

$$
Y_{1}, Y_{2}=\beta_{0}+\beta_{1} I_{1}+\beta_{2} I_{2}+\beta_{3} I_{3}+\beta_{4} X_{1}+\beta_{5} X_{2}+\beta_{6} X_{3}+\beta_{7} X_{3}^{2}+\epsilon
$$

where $I_{i}, i=1,2,3$; denote indicator variables for differences in intercepts corresponding to years and $X_{3}$ denotes the elevation at a location, in units of $100 \mathrm{ft}$. A contour map for $X_{3}$ is given in Figure 4.

The $R^{2}$ values for the models of $Y_{1}$ and $Y_{2}$ are 0.71 and 0.72 , respectively, as compared to 0.68 and 0.69 in model 4 . The hypothesis $H_{0}: \beta_{6}=\beta_{7}=0$ is rejected $(p<0.001)$ in each case $\left(F_{2,300}=15.0\right.$ and $\left.F_{2,300}=14.2\right)$, which implies that elevation is a significant additional predictor variable for both $Y_{1}$ and $Y_{2}$. It is apparent from the coefficients of the indicator variables in Table 6 that the predicted DOY differs by as many as 20.3 days for $Y_{1}$ and 16.6 days for $Y_{2}$ over the four years.

Coefficients for models of the form in (6) were calculated for each year to test whether, under the assumption of equal partial slopes for $X_{1}$ and $X_{2}$, the elevation coefficients are also the same for every year. The test statistics for $Y_{1}$ and $Y_{2}$ are $F_{6 ., 300}=0.98$ and $F_{6,300}=1.17$, respectively, which imply that there is no statistical evidence that these coefficients differ. Other models which contained interaction terms of elevation and latitude were also obtained to test whether elevation has a relative, as opposed to absolute, effect at a given latitude. Such additional terms were not significant. Consequently, we recommend the use of model 6, with estimated coefficients in Table 6 , for the four years.

The contour lines for the estimated DOY of $Y_{2}$ in 1985 are given in Figure 2B. Note that the estimated equations for the other three years use the same estimates of $b_{3}$ through $b_{7}$, hence their contour lines merely shift those in Figure $2 \mathrm{~B}$ by the constants given in Table 6 . As before, once the new intercept is determined for a given year, predictions of DOY at other locations could be predicted for that year.

\subsection{Other Variables}

The residual plots from model 6 are given in Figure 5. Though elevation is a highly significant factor, the residual plots seem not to have changed a great deal from those in Figure 3. The correlation of these residuals with soil moisture, soil temperature and precipitation is under current investigation.

\section{Discussion}

\subsection{Comparison of $Y_{1}$ and $Y_{2}$.}

There is a consistent difference in the slopes of $Y_{1}$ and $Y_{2}$ in the models with longitude. In Table 2, the slopes for $Y_{1}$ are lower than the corresponding slopes for $Y_{2}$, and the $Y_{1}$ intercepts are also larger. The same result holds for the estimated partial slopes for longitude and for the intercepts for the models in Table 4 and Table 6 . A new variable $D=Y_{1}-Y_{2}$ was created, and investigated using models 2,3 and 6 . In each case, the longitude term is significant. The effect of this phenomenon for the present data is that $Y_{1}$ tends to exceed $Y_{2}$ for locations in the west, with the reverse being true in the east. 


\subsection{Comparison with Other Predictive Models.}

used. Let

Models of insect first appearance based on cumulative degree-days are also widely

$$
X_{4}=\text { predicted date of first catch based on cumulative } 171.5 \text { degree-days. }
$$

$X_{4}$ was obtained for all sampling locations in 1983 and 1984 where weather data were available at adjacent weather stations. Consider the simple linear models

$$
Y_{1}, Y_{2}=\beta_{0}+\beta_{1} X_{4}+\epsilon
$$

Model 7 was compared to model 1 using all locations where $Y_{1}, Y_{2}$ and $X_{4}$ were available. The $r^{2}$ values for $Y_{1}$ and $Y_{2}$ from model 1 are 0.74 and 0.77 in 1983, and 0.75 and 0.78 in 1984; whereas the comparable $r^{2}$ values from model 7 are $0.64,0.66,0.53$ and 0.58 , respectively. These results imply that $X_{1}$, latitude, is a better simple linear predictor of $Y_{1}$ or $Y_{2}$ than $X_{4}$, for both years.

In estimated model $7, \beta_{0}$ is often significantly different from 0 and $\beta_{1}$ from 1 . Moreover, a quadratic $X_{4}$ term is often significant. Research is in progress to investigate $X_{4}$ further and to incorporate it into the present prediction equations.

\subsection{Identification of Other Variables.}

This general procedure of analyzing residuals from regression models on a map has identified elevation as a significant predictor variable. Elevation may be a significant factor due to its effect on wind flow. Data are currently being gathered with uniform traps and monitoring procedures on catch of the corn earworm in Texas. It is expected that, under these more controlled conditions with smaller expected sampling errors, this procedure of spatial residual analysis may identify additional variables of interest affecting insect occurrence.

\section{Summary}

This study demonstrates that the date of first catch of the corn earworm in central U.S. is correlated with certain geographical variables of the sample site, namely latitude, longitude and elevation. The resulting regression models have high $R^{2}$ with common partial slopes from year to year; thus providing a theoretical basis for a predictive model. Research is in progress to obtain prediction error estimates and thus validate the model by predicting dates for first catch for a given year from the remaining three years.

\section{Acknowledgments}

The authors are grateful to P.D. Lingren for his role in initiating the project and for many insightful discussions on the topic. Douglas Wunneburger, Mapping Science Lab, was instrumental in setting up the GIS interface, and J. Esquivel and D.V. Peterson, ARS, were helpful in reviewing an early draft. We also appreciate many helpful suggestions from an anonymous reviewer. This research was supported in part by USDA Coop Grant 58-6202-4052 entitled Population Dispersal Rates of the Corn Earworm to the senior author. 
References:

Cressie, N. 1993. Statistics for Spatial Data. Revised Ed. Wiley, N.Y.

ENSI. 1991. ARC/INFO User's Guide. Environmental Systems Research Institute Inc., CA.

Goodenough, J.L., J.A. Witz, J.D. Lopez, \& A.W. Hartstack. 1987. A system for wide area survey of Heliothis. In Proc. 1987 Beltwide Cotton Production Research Conf. Dallas, TX.

Goodenough, J.L., J.A. Witz, J.D. Lopez \& A.W. Hartstack. 1988. Patterns of occurrence of Heliothis spp. (Lepidoptera: Noctuidae), 1983-1985. J. Econ. Entomol. 81:16241630 .

MathSoft. 1993. S-PLUS Guide to Statistical and Mathematical Analysis. Version 3.2. MathSoft, Inc., Seattle.

Neter, J., W. Wasserman \& M.H. Kutner. 1989. Applied Linear Regression Models. 2 Ed. Irwin, Boston. 
Table 1. Parameter Estimates, Standard Errors, and $r^{2}$ for Model 1 with Latitude, $X_{1}$
A. Results for $Y_{1}$
Results for $Y_{2}$

\begin{tabular}{|l|l|l|l|l|l|l|}
\hline Year & $b_{0}(\mathrm{se})$ & $b_{1}(\mathrm{se})$ & $r^{2}$ & $b_{0}(\mathrm{se})$ & $b_{0}(\mathrm{se})$ & $r^{2}$ \\
\hline 1983 & $-156.4(25.2)$ & $7.91(0.74)$ & 0.67 & $-148.5(22.3)$ & $7.56(0.65)$ & 0.69 \\
\hline 1984 & $-197.4(21.3)$ & $9.01(0.59)$ & 0.73 & $-182.6(19.3)$ & $8.47(0.54)$ & 0.75 \\
\hline 1985 & $-162.2(22.2)$ & $8.55(0.62)$ & 0.65 & $-172.2(18.9)$ & $8.59(0.51)$ & 0.71 \\
\hline 1986 & $-88.6(25.6)$ & $6.66(0.69)$ & 0.43 & $-133.2(22.7)$ & $7.57(0.60)$ & 0.54 \\
\hline combined & $-160.2(12.5)$ & $8.34(0.35)$ & 0.61 & $-170.0(10.7)$ & $8.41(0.29)$ & 0.67 \\
\hline
\end{tabular}

Table 2. Parameter Estimates, Standard Errors, and $r^{2}$ for Model 2 with Longitude, $X_{2}$
A. Results for $Y_{1}$
B. Results for $Y_{2}$

\begin{tabular}{|l|l|l|l|l|l|l|}
\hline Year & $b_{0}(\mathrm{se})$ & $b_{1}(\mathrm{se})$ & $r^{2}$ & $b_{0}(\mathrm{se})$ & $b_{1}(\mathrm{se})$ & $r^{2}$ \\
\hline 1983 & $333.7(53.4)$ & $-2.33(0.56)$ & 0.23 & $302.0(48.5)$ & $-2.04(0.51)$ & 0.21 \\
\hline 1984 & $318.8(94.4)$ & $-2.11(1.01)$ & 0.05 & $256.0(88.5)$ & $-1.47(0.95)$ & 0.03 \\
\hline 1985 & $374.2(56.3)$ & $-2.59(0.63)$ & 0.14 & $338.2(52.3)$ & $-2.22(0.58)$ & 0.11 \\
\hline 1986 & $322.4(36.4)$ & $-1.91(0.42)$ & 0.14 & $272.7(36.0)$ & $-1.43(0.42)$ & 0.08 \\
\hline combined & $377.9(24.6)$ & $-2.66(0.27)$ & 0.20 & $331.7(23.4)$ & $-2.21(0.26)$ & 0.15 \\
\hline
\end{tabular}

Table 3. Results for Models with Common Slopes but Different Intercepts

\begin{tabular}{|l|l|l|l|}
\hline Dep. Var. & Indep. Var. & $\begin{array}{l}\text { Common Slope } \\
\text { with (se) }\end{array}$ & Model $r^{2}$ \\
\hline$Y_{1}$ & $X_{1}$ & $7.97(0.34)$ & 0.65 \\
\hline$Y_{2}$ & $X_{1}$ & $8.11(0.30)$ & 0.69 \\
\hline$Y_{1}$ & $X_{2}$ & $-2.19(0.30)$ & 0.23 \\
\hline$Y_{2}$ & $X_{2}$ & $-1.77(0.28)$ & 0.19 \\
\hline
\end{tabular}


Table 4. Parameter Estimates, Standard Errors, and $R^{2}$ for Model 3 with Latitude, $X_{1}$ and Longitude, $X_{2}$, for Central U.S.
A. Results for $Y_{1}$
B. Results for $Y_{2}$

\begin{tabular}{|l|l|l|l|l|l|l|l|l|}
\hline Year & $b_{0}(\mathrm{se})$ & $b_{1} \quad(\mathrm{se})$ & $b_{2}(\mathrm{se})$ & $R^{2}$ & $b_{0}(\mathrm{se})$ & $b_{1} \quad(\mathrm{se})$ & $b_{2} \quad(\mathrm{se})$ & $R^{2}$ \\
\hline 1983 & 28.42 & 7.65 & -1.82 & 0.82 & -18.93 & 7.36 & -1.27 & 0.82 \\
& $(49.72)$ & $(0.55)$ & $(0.46)$ & & $(43.44)$ & $(0.50)$ & $(0.40)$ & \\
\hline 1984 & -80.09 & 8.86 & -1.20 & 0.75 & -110.57 & 8.40 & $-0.74 \mathrm{~ns}$ & 0.75 \\
& $(55.42)$ & $(0.58)$ & $(0.53)$ & & $(50.66)$ & $(0.54)$ & $(0.48)$ & \\
\hline 1985 & 85.14 & 8.28 & -2.62 & 0.72 & -33.51 & 8.23 & -1.40 & 0.72 \\
& $(51.22)$ & $(0.59)$ & $(0.51)$ & & $(47.24)$ & $(0.53)$ & $(0.47)$ & \\
\hline 1986 & 87.42 & 6.10 & -1.71 & 0.42 & -150.37 & 7.47 & $0.24 \mathrm{~ns}$ & 0.50 \\
& $(72.64)$ & $(0.85)$ & $(0.71)$ & & $(64.05)$ & $(0.78)$ & $(0.61)$ & \\
\hline combined & 60.27 & 7.76 & -2.17 & 0.64 & -73.16 & 8.00 & -0.90 & 0.66 \\
& $(31.39)$ & $(0.35)$ & $(0.30)$ & & $(28.09)$ & $(0.32)$ & $(0.27)$ & \\
\hline
\end{tabular}

Table 5. $R^{2}$ and Results of Testing Partial Coefficients of Second Degree Terms in Model 5
A. Results for $Y_{1}$
B. Results for $Y_{2}$

\begin{tabular}{|l|l|l|l|l|l|l|l|l|}
\hline Year & $b_{3}$ & $b_{4}$ & $b_{5}$ & $R^{2}$ & $b_{3}$ & $b_{4}$ & $b_{5}$ & $R^{2}$ \\
\hline 1983 & $\mathrm{~ns}$ & $\mathrm{~ns}$ & $\mathrm{~ns}$ & 0.86 & $\mathrm{~ns}$ & $\mathrm{~ns}$ & .01 & 0.85 \\
\hline 1984 & $\mathrm{~ns}$ & $\mathrm{~ns}$ & $\mathrm{~ns}$ & 0.76 & $\mathrm{~ns}$ & $\mathrm{~ns}$ & $\mathrm{~ns}$ & 0.76 \\
\hline 1985 & $\mathrm{~ns}$ & $\mathrm{~ns}$ & $\mathrm{~ns}$ & 0.73 & $\mathrm{~ns}$ & $\mathrm{~ns}$ & $\mathrm{~ns}$ & 0.74 \\
\hline 1986 & $\mathrm{~ns}$ & $\mathrm{~ns}$ & $\mathrm{~ns}$ & 0.44 & $\mathrm{~ns}$ & $\mathrm{~ns}$ & $\mathrm{~ns}$ & 0.53 \\
\hline combined & $\mathrm{ns}$ & $\mathrm{ns}$ & $\mathrm{ns}$ & 0.66 & $\mathrm{~ns}$ & $\mathrm{~ns}$ & .01 & 0.68 \\
\hline
\end{tabular}

Table 6. Estimated Regression Coefficients for Model 6 with the Elevation Variable

\begin{tabular}{|l|l|l|l|l|l|l|l|ll|l|}
\hline Coefficient & $b_{0} \quad(\mathrm{se})$ & $b_{1} \quad(\mathrm{se})$ & $b_{2} \quad(\mathrm{se})$ & $b_{3}(\mathrm{se})$ & $b_{4} \quad(\mathrm{se})$ & $b_{5} \quad(\mathrm{se})$ & $b_{6} \quad(\mathrm{se})$ & $b_{7} \quad(\mathrm{se})$ \\
\hline for $Y_{1}$ & 140.4 & $-9.7^{\mathrm{ns}}$ & $\begin{array}{l}2.8^{\mathrm{ns}} \\
(4.9)\end{array}$ & $\begin{array}{l}10.6 \\
(5.1)\end{array}$ & $\begin{array}{l}6.71 \\
(0.50)\end{array}$ & $\begin{array}{l}-2.80 \\
(0.39)\end{array}$ & $\begin{array}{l}8.16 \\
(2.89)\end{array}$ & $\begin{array}{l}-0.555 \\
(0.268)\end{array}$ \\
\hline for $Y_{2}$ & $\begin{array}{l}(42.7) \\
\end{array}$ & $\begin{array}{l}-2.9^{\mathrm{ns}} \\
(37.1)\end{array}$ & $\begin{array}{l}-8.5^{\mathrm{ns}} \\
(4.7)\end{array}$ & $\begin{array}{l}1.0^{\mathrm{ns}} \\
(4.6)\end{array}$ & $\begin{array}{l}8.1^{\mathrm{nS}} \\
(4.8)\end{array}$ & $\begin{array}{l}7.59 \\
(0.35)\end{array}$ & $\begin{array}{l}-1.59 \\
(0.36)\end{array}$ & $\begin{array}{l}2.62 \\
(1.17)\end{array}$ & $\begin{array}{l}-0.0059^{\mathrm{ns}} \\
(0.041)\end{array}$ \\
\hline
\end{tabular}

ns denotes nonsignificant partial test 


\section{Appendix Figure 1. Contour lines and Greyscale Contours for Y2}

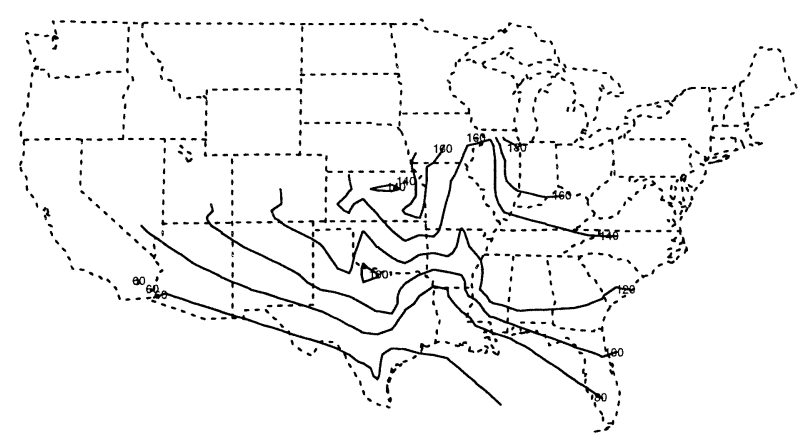

1983

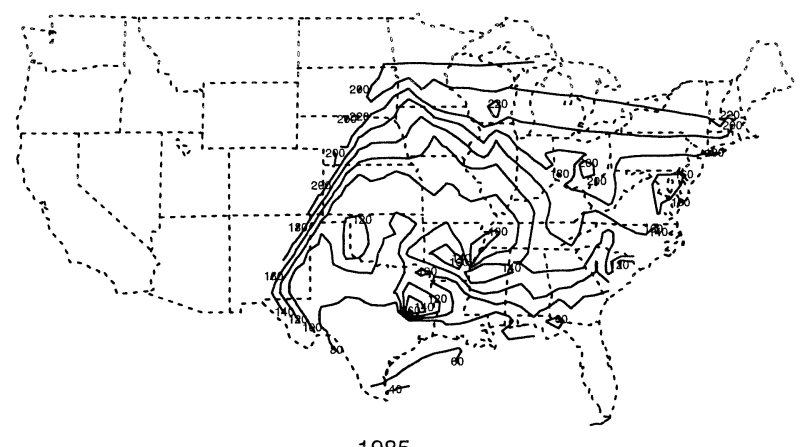

1985

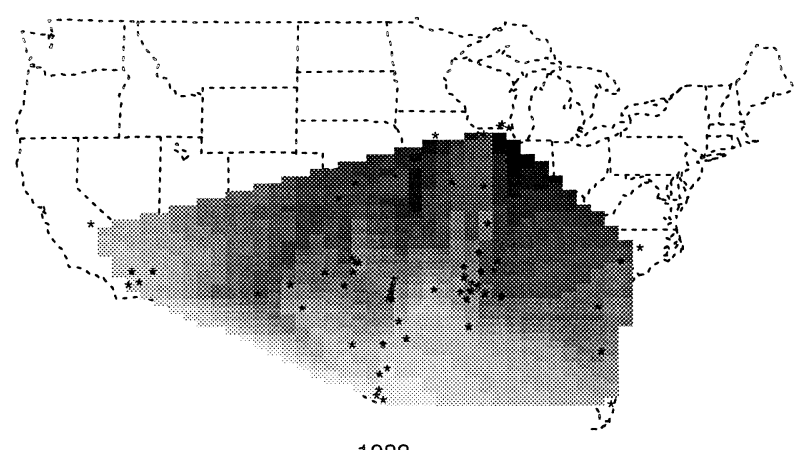

1983

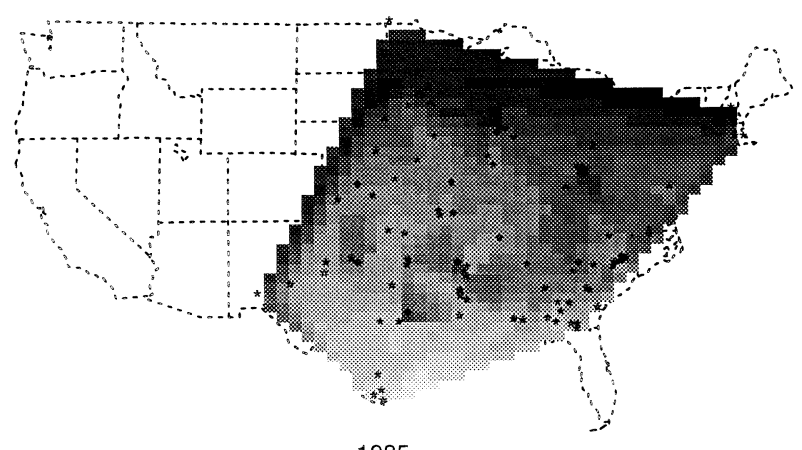

1985

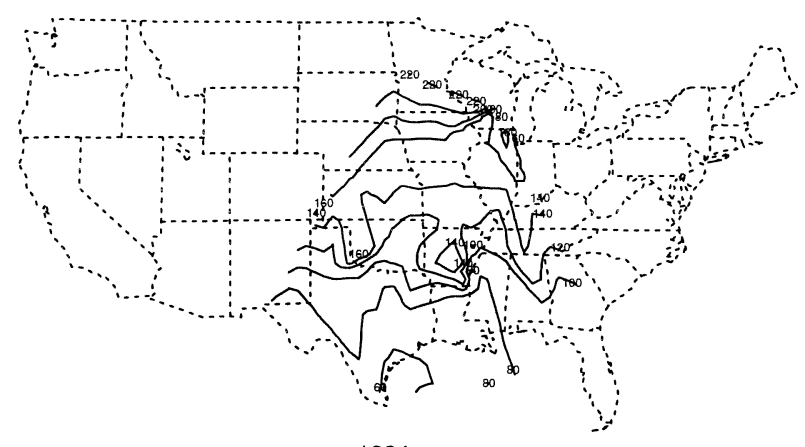

1984
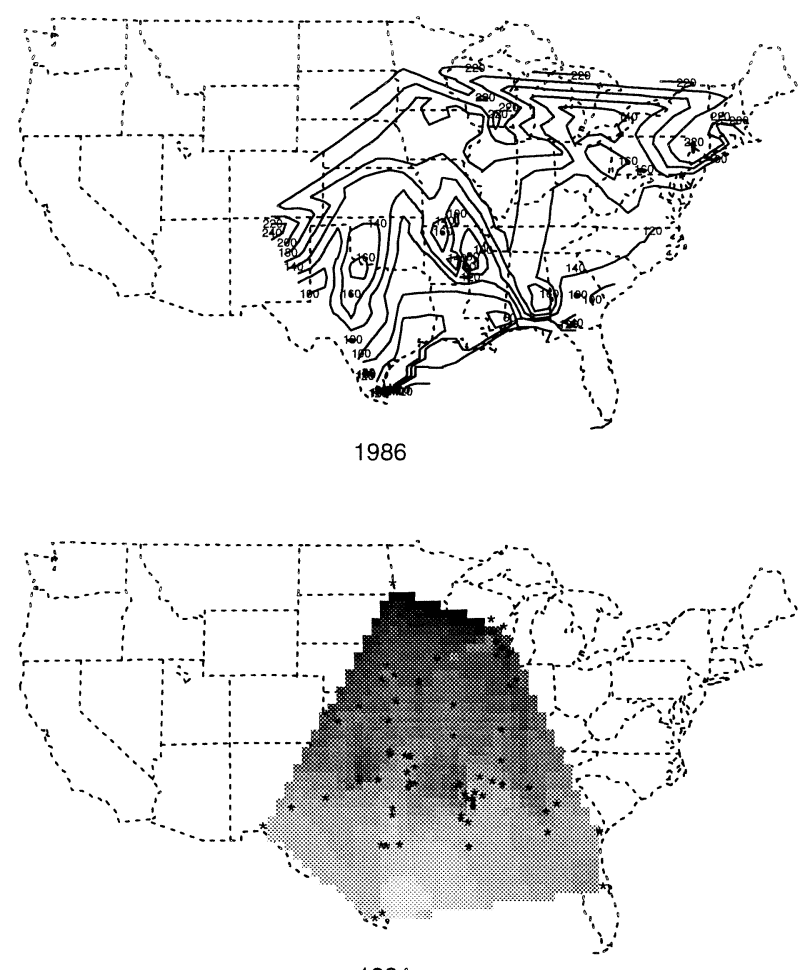

1984

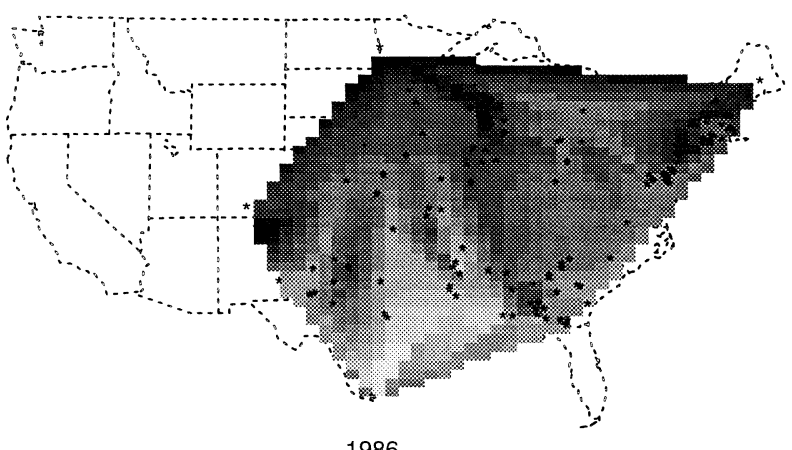

1986 
Figure 2A. Regression lines for Y2 vs latitude or longitude
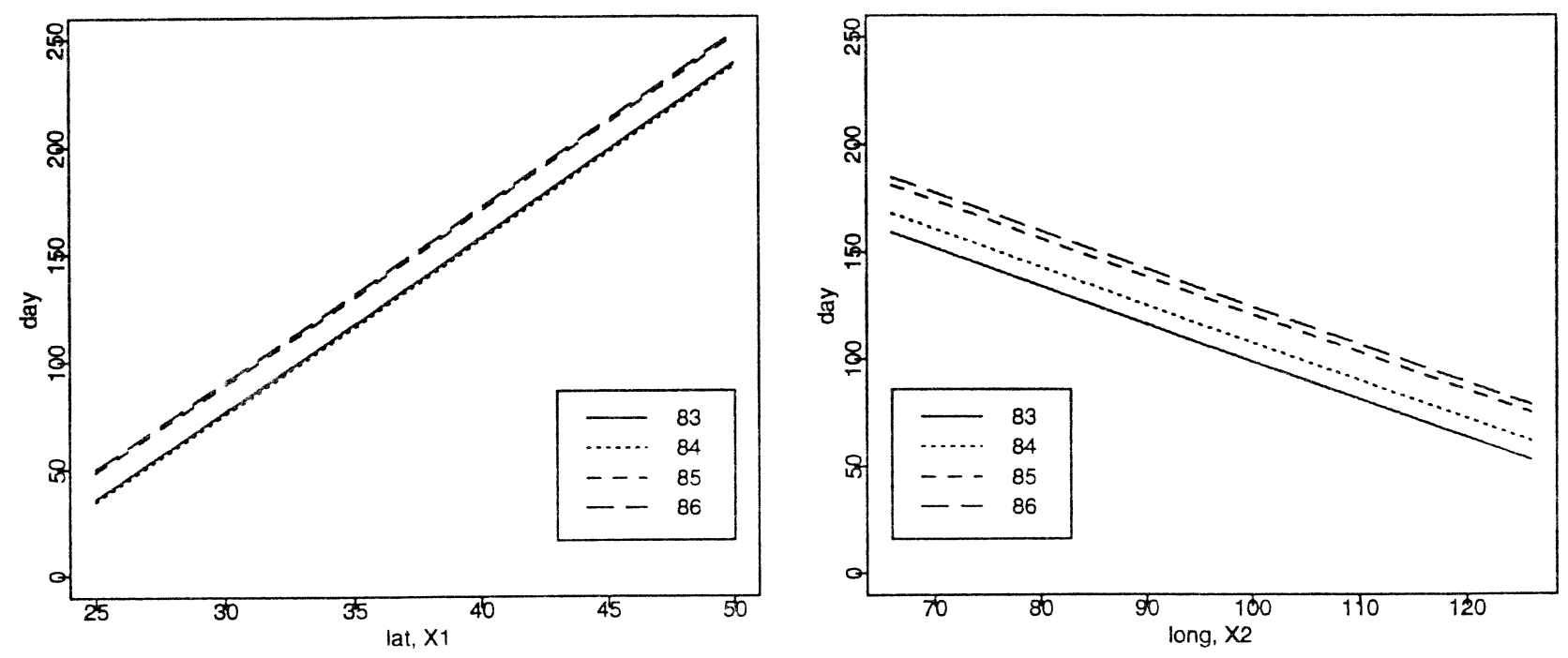

Figure 2B. Contours for predicted Y2 from model 6 for 1985

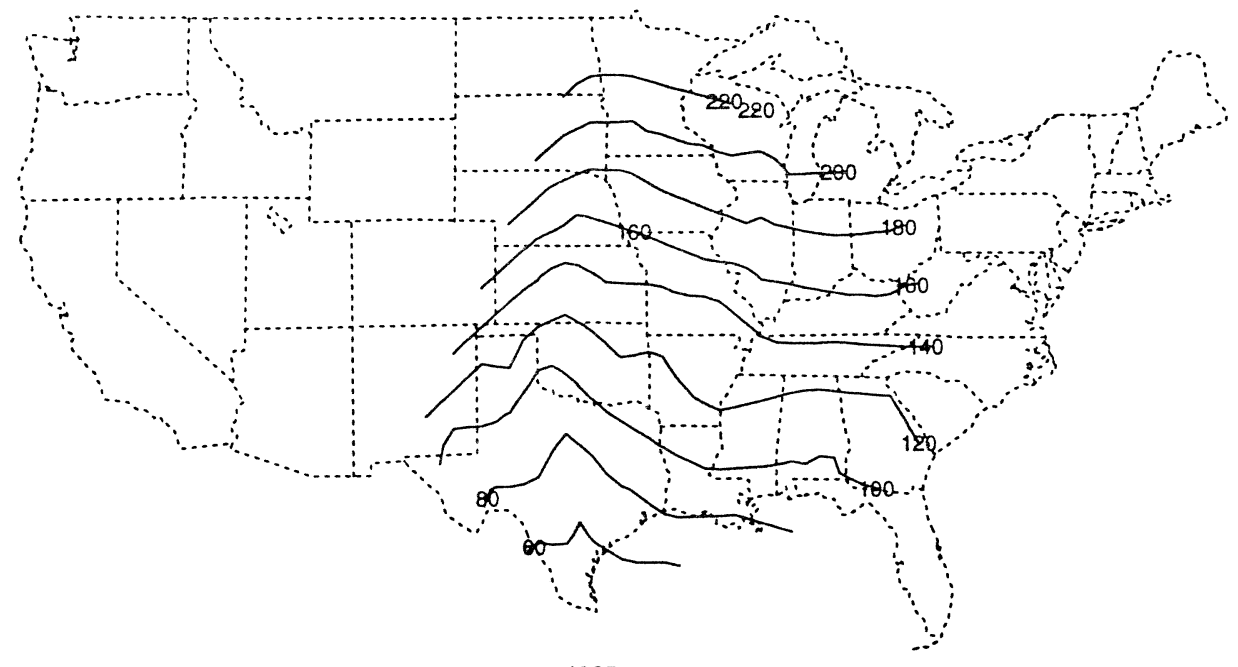

1985 
Figure 3. Greyscale contours for residuals of Y2 from

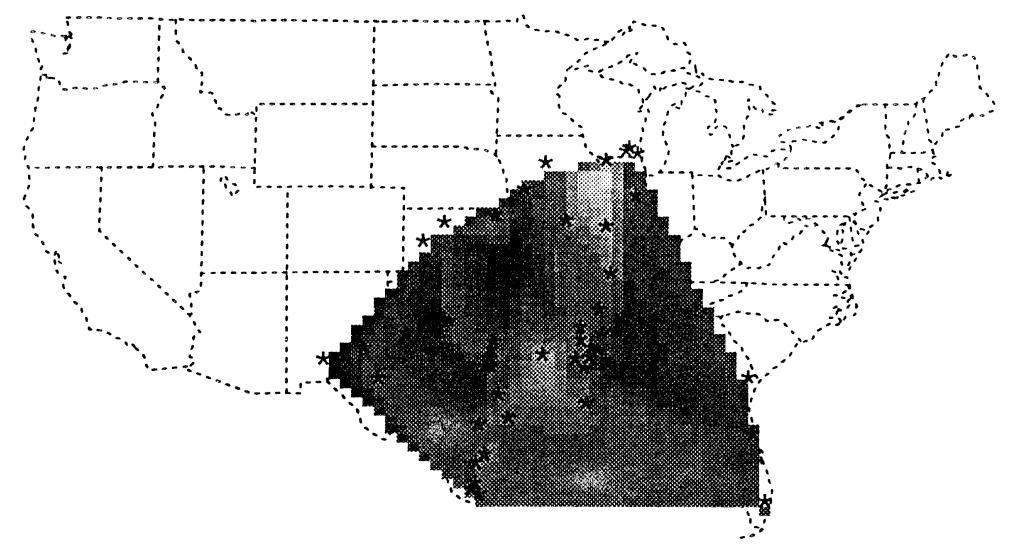

1983

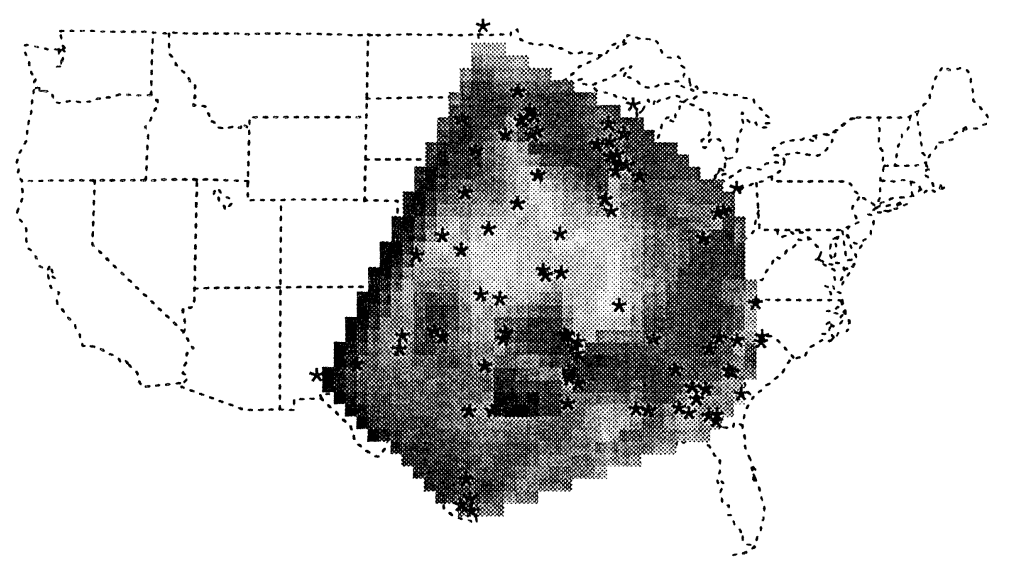

1985

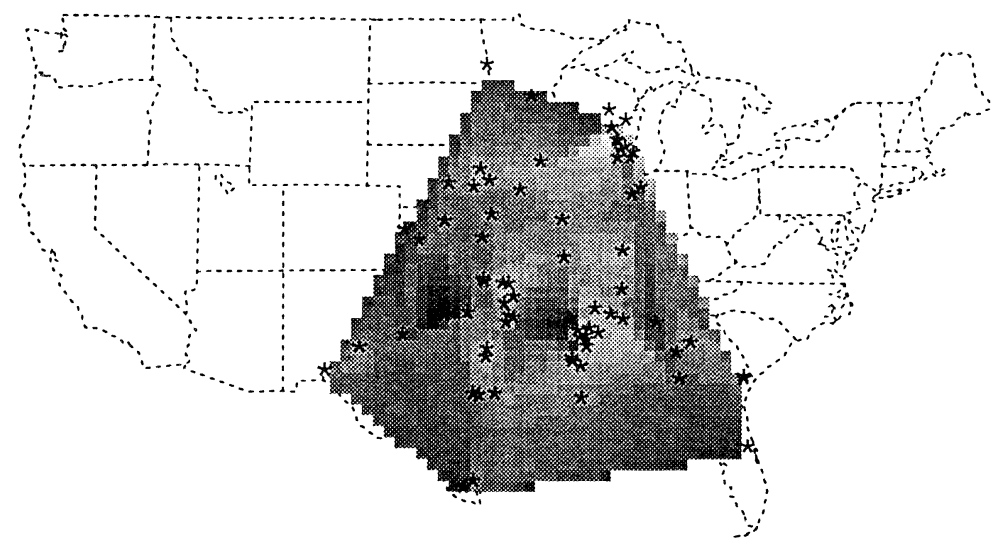

1984

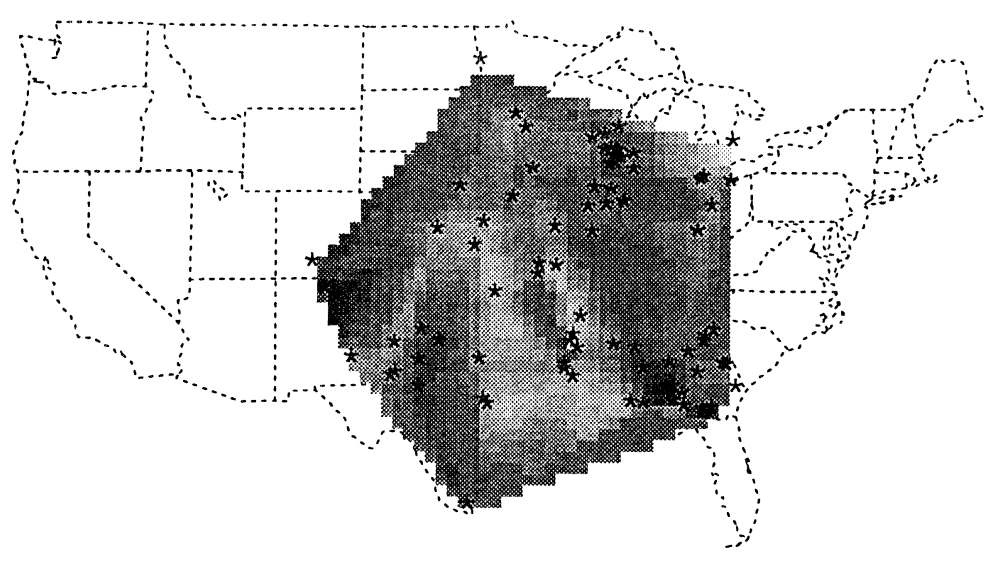

1986 
Figure 4. Elevation contour map of USA 
Figure 5. Greyscale contours for residuals of Y2 from Model 6 with latitude, longitude, elevation and elevation*elevation

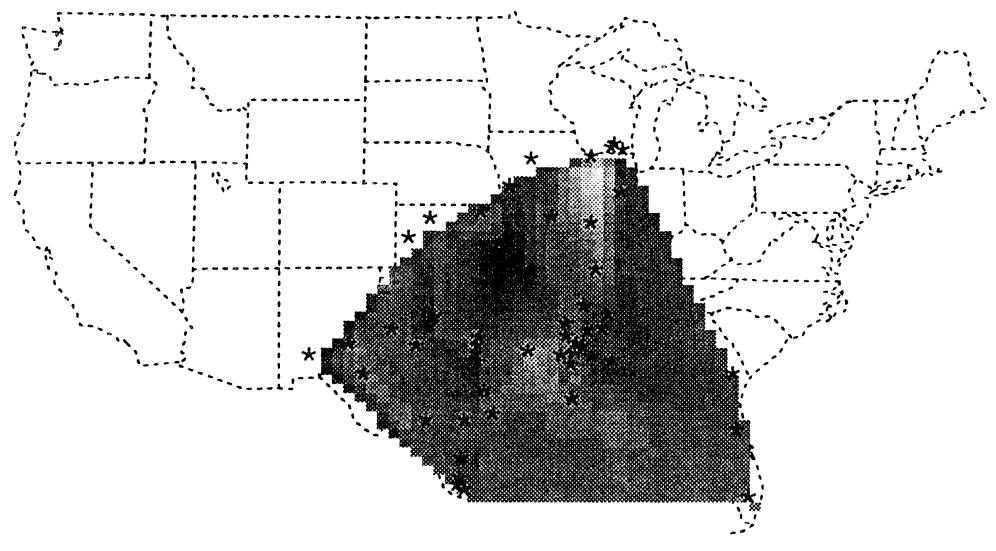

1983

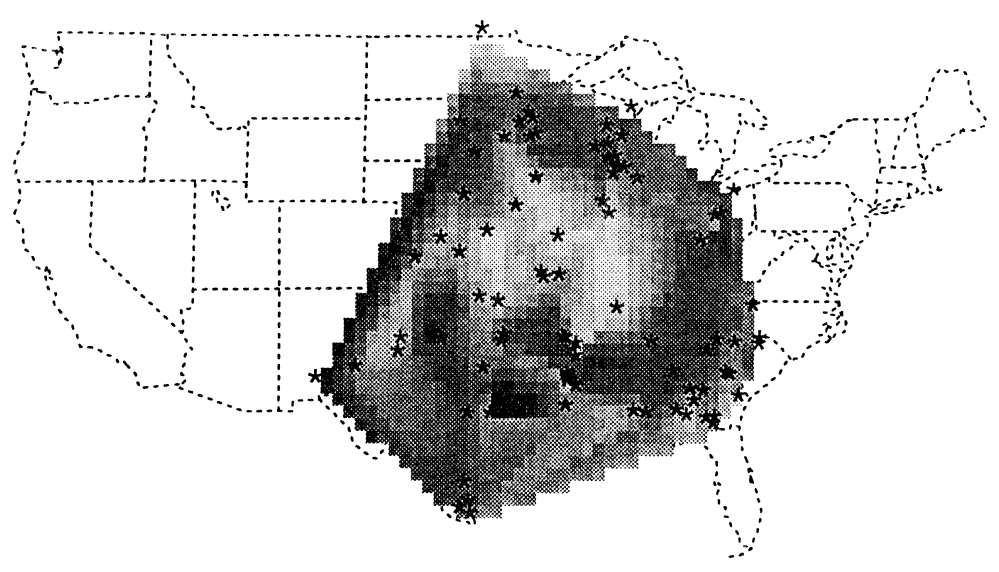

1985

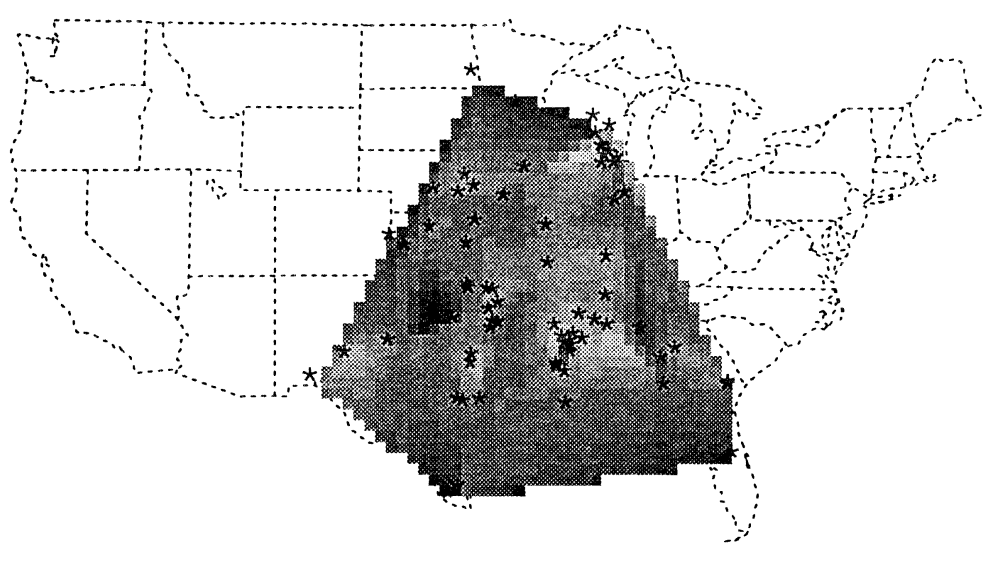

1984

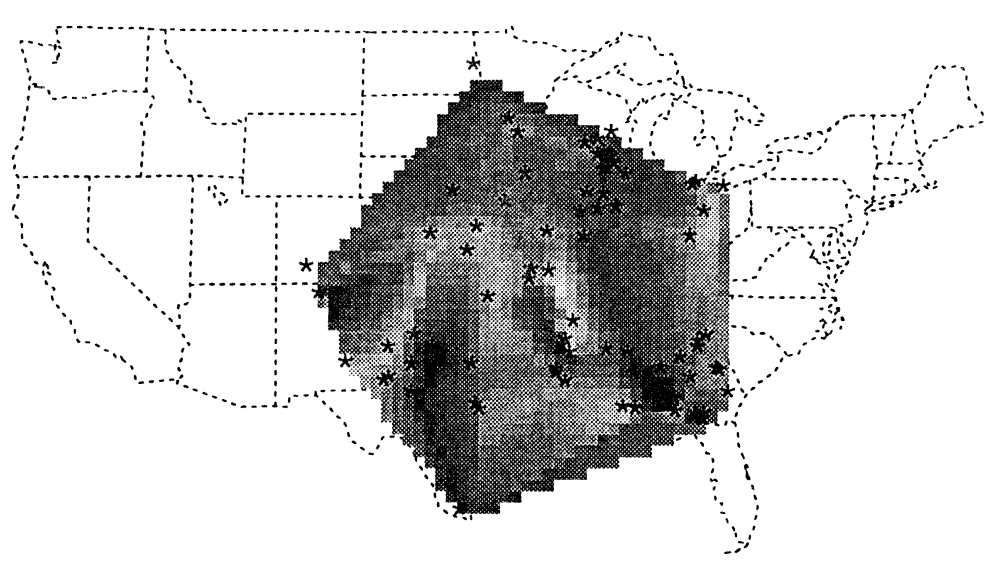

1986 